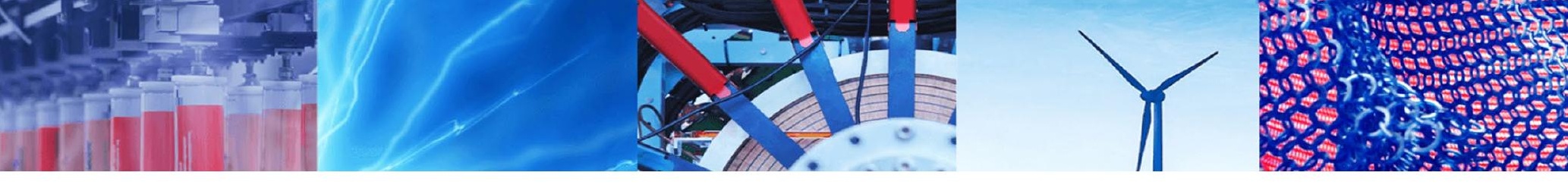

Research Article

\title{
Picasso's Acrobat Family in focus: an investigation of materials and techniques of an iconic work in the collection of the Gothenburg Museum of Art
}

\author{
David Buti $^{1,4} \cdot$ Mariateresa Pullano $^{2}$ (D) Eleonora Papa ${ }^{3} \cdot$ Eva Nygårds $^{2} \cdot$ Loa Ludvigsen $^{1}$ (D) Jørgen Wadum $^{1,5}$ (D)
}

Received: 18 December 2018 / Accepted: 2 July 2020 / Published online: 22 July 2020

(c) Springer Nature Switzerland AG 2020

\begin{abstract}
The Acrobat Family is one of Pablo Picasso's highly rated works from his Rose Period. The painting was one of the first two works by the artist acquired by the Stein's, and in 1922 it came to Gothenburg Art Museum. In catalogues, the materials used for the work are described as a mix of gouache, pastel, watercolour and Indian ink on cardboard; however, the information is often contradictory and inaccurate. An extensive scientific investigation of the painting was carried out to unravel Picasso's technique, materials and the object's condition. The results indicate that the cardboard is of an acidic nature and the techniques used by the artist are based on different binding media, possibly oil, wax and polysaccharides. Interesting results have been achieved on the discoloured blue areas, where ultramarine blue and Prussian blue are the main components.
\end{abstract}

Keywords Rose period · Cardboard · Material characterization · Fading · Ultramarine blue · Prussian blue

\section{Introduction}

In February 1905, Pablo Picasso exhibited 33 works and some drawings at the Galerie Serrurier in Paris. The first eight works in the exhibition were listed under the common title 'Les Saltimbanques', Acrobat Family was most likely one of the eight works [1].

From a review of the poet Guillaume Apollinaire in La Plume in May 15, 1905 it is possible to identify Acrobat Family, poetically described as: "Primiparous mother no longer expect the baby to arrive, perhaps because of certain ill-omened, chattering ravens. Miracle! They give birth to future acrobats in the midst of pet monkeys [...]" [2]. Since all the works in Serruries's exhibition did not have any other significant description apart from 'Les
Saltimbanques', by reading the review written by Apollinaire, it is possible to identify most of them [3].

Among the works exhibited two themes can be distinguished, one focused on the family, depicting the fatherhood of the harlequin, and the second emphasizing the circus where the harlequin is associated with the acrobats. In Acrobat Family Picasso merges these themes in a pyramidal composition comparable to the depiction of the holy family in renaissance art.

In October 1905 the famous collector and art patron Leo Stein bought it together with the Girl with a Basket of Flowers, something that helped launching Picasso's career. Looking at the catalogue "Steins Collect: Matisse, Picasso, and the Parisian Avant-Garde" there are two pictures recording the display of the painting in

David Buti, david.buti@ispc.cnr.it | ${ }^{1}$ Centre for Art Technological Studies and Conservation, Statens Museum for Kunst, Sølvgade 48-50, 1307 Copenhagen, Denmark. ${ }^{2}$ Göteborgs Konstmuseum, Götaplatsen, 41256 Göteborg, Sweden. ${ }^{3}$ Moderna Museet, Box 16382 , 10327 Stockholm, Sweden. ${ }^{4}$ Present Address: Istituto di Scienze del Patrimonio Culturale - Consiglio Nazionale delle Ricerche (ISPC-CNR), Via Madonna del Piano, 10 - 50019, Sesto Fiorentino, Firenze, Italy. ${ }^{5}$ Present Address: Wadum Art Technological Studies (WATS), Åløkkevej 24, 2720 Vanløse, Denmark. 
1907 and in 1908 on the north wall of the apartment of Michael Stein, Leo and Gertrude's older brother [4]. Leo Stein left Paris in 1916, leaving his Picasso collection behind, including Acrobat Family, which by now was sold to Walter Halvorsen, a Norwegian artist, art dealer and a student of Matisse. He offered the work to the National Museum in Stockholm but the institution had to decline the opportunity to buy it.

Halvorsen contacted Conrad Pineus, a businessman and art collector from Gothenburg, at the time one of the greatest art patrons in Sweden. He established an extensive collection of Nordic contemporary art, enriched with a quite important number of French modern artworks. Due to an unfortunate stock investment in 1920, Pineus was forced to sell his French collection, offering the Acrobat Family to the Gothenburg Museum of Art in 1922. From that moment the Acrobat Family became, and still is, one of the highlights of the museum $[5,6]$.

In his turbulent and early creative period Picasso experimented with his materials and tried to explore new painting techniques. Looking at many of the works from this period, the artist seems to strive to create an opaque appearance on the pictorial surface. This effect is highly achieved in Acrobat Family, where the surface is left unvarnished, the figures are drawn with a thick black contour and the brushstrokes of paint are bold and perfectly balanced between dense and transparent colours. It is remarkable how Picasso intentionally leaves the yellow-brownish colour of the cardboard unpainted in large areas in order to achieve a result of a magnificent level of harmony between the rose, the blues and the earthy tones.

From different catalogue sources, the most common medium used in the artist's production on cardboard between 1905 and 1906 appears to be gouache. In the Acrobat Family this is also suggested by: (1) the general matt appearance of the unvarnished surface, (2) the look of the pigments under magnification, which appear poorly bounded and embedded into the fibres and (3) the presence of holes left by evaporated water bubbles (Fig. 2a-f). However, under reflected and raking light some areas appear shiny, suggesting the use of different binders and thus different painting techniques (Fig. $2 \mathrm{~g}$ ).

There are several works from this period that can be compared to Acrobat Family in terms of style and topic. In two of them, the Saltimbaque in Profile and Girl in a Chemise, it is reported that Picasso used a technique called 'essence', which is oil paint that has been heavily diluted with turpentine, causing the leaching of much of the oil and thus attaining a semi-transparent matte wash $[7,8]$. The essence technique could be the clue to explain the different visual appearance (opaque vs. shiny) of the paint layer.

Because of the work's particularly sensitive materials (the reason why the museum has always been restrictive in terms of loans) and the lack of documentation about the condition of the painting, recently, a more thorough examination was initiated to research its current state.

The first step was a visual examination to compare the present appearance with archival photo documentation and old catalogue pictures [9]. Here it became clear that many areas have faded over the years and some now appear severely discoloured (Fig. 1a, b). The images reported in Fig. 1 cannot be considered reliable in terms of colour rendering since they were taken almost 50 years apart with different set-ups, but can still be used to document the degree of discolouration of certain areas. The most faded paints seem to be the blue of the curtain on the right side of the painting and the greenish blue background.

Technical photography (infrared, infrared false colour, microphotography) provided valuable information about the materials distribution and together with fibre analyses showed also a plausible relation between the degradation of the cardboard and the pigment discolouration [9]. From the mechanical point of view the most sensitive and degraded areas are the edges and corners of the board, which show a delamination in the layered structure (Fig. 2h), probably also related to handling. This delamination has probably played a role in the mechanical loss of colour together with the discolouration. Lately, analyses by X-ray Fluorescence (XRF), Fourier Transform Infrared (FTIR), and Fibre Optics Reflectance Spectroscopy (FORS) were carried out to achieve a better understanding of the painting technique, identify the materials composition, and provide explanations for the discolouration.

\section{Experimental}

\subsection{Optical microscopy and technical photography}

Microphotographs were taken with a Leica M80 stereo microscope, using 10x, 25x, and 60x magnification.

Visible and infrared imaging was carried out using a modified Canon EOS 5D Mark II camera, with an EF50mm $\mathrm{f} / 2,5$ Compact Macro Lens, and B +W $77 \mathrm{~mm}$ UV/IR Cut MRC $486 \mathrm{M}$ and RG830 filters. For illumination tungstenhalogen lamps were positioned at ca. $20^{\circ}$ to the painting. Near infrared false colour images (IRFC) were obtained following the protocol in the AIC guide [10]. 
a

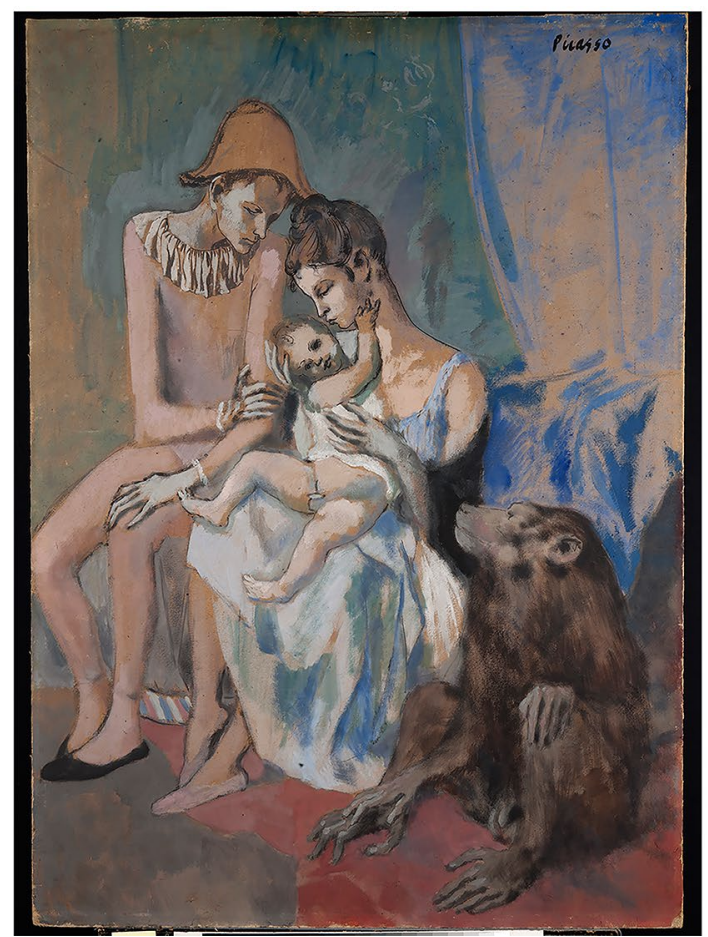

Fig. 1 Pablo Picasso, Acrobat Family, 1905, $104 \times 75 \times 0.3 \mathrm{~cm}$, GKM699. Current state of the artwork (a), compared to a printed archival document from 1964 (b). $\odot$ of the reproductions of works b

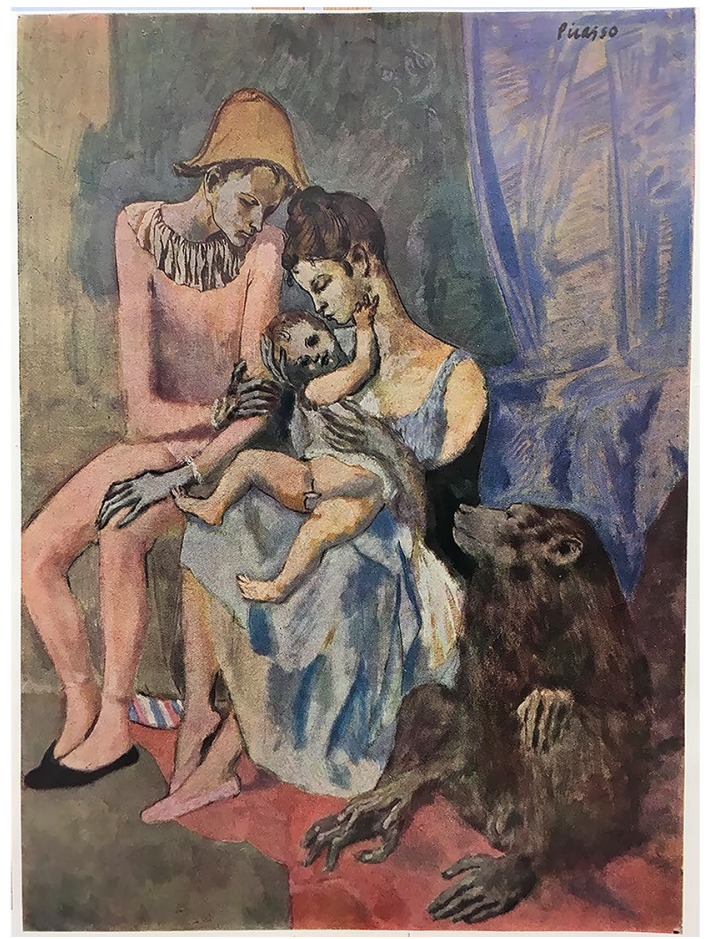

by Pablo Picasso: Pablo Picasso's Estate. VEGAP. Madrid, 2020. Permission to reproduce courtesy of VEGAP

\section{$2.2 \mathrm{XRF}$}

Elemental analysis was carried out using the Elio portable X-ray fluorescence system from XGlab X and Gamma Ray Electronics. Measurements were conducted at $40 \mathrm{kV}$ and $100 \mu \mathrm{A}$ with an integration time of $120 \mathrm{~s}$. The spatial resolution was about $1 \mathrm{~mm}^{2}$.

\subsection{FORS}

FORS was performed with an FS4 Spectroradiometer (Malvern Panalytical). Spectra were collected in the range of $350-2500 \mathrm{~nm}$, with a resolution of $3 \mathrm{~nm}$ (UV-Vis) and $10 \mathrm{~nm}$ (NIR). The light probe was set at $45^{\circ}$ from the surface normal, while the collecting fibre was held perpendicularly to the sample. The sampling area was about $3 \mathrm{~mm} \varnothing .64$ spectra were averaged for each sample. The geometry adopted for the acquisition of the spectra is reported in Aceto et al. [11].

\subsection{FTIR}

FTIR spectra were recorded in reflection mode using the Alpha spectrometer (Bruker Optics). The measurements were carried out in the $7000-375 \mathrm{~cm}^{-1}$ range at a resolution of $4 \mathrm{~cm}^{-1}$ with 128 scans. The spatial resolution is about 28 $\mathrm{mm}^{2}$ and the probe head-to-surface distance is higher than $1 \mathrm{~cm}$.

\section{Results and discussion}

\subsection{Support and painting technique}

The XRF spectra of the cardboard support contain iron $(\mathrm{Fe})$ and calcium $(\mathrm{Ca})$ as the main elements, together with minor amounts of barium (Ba), zinc ( $\mathrm{Zn}$ ), sulphur (S), copper $(\mathrm{Cu})$, lead $(\mathrm{Pb})$ and strontium $(\mathrm{Sr})$, and traces of potassium (K), silicon (Si) and aluminium (Al). Variable amounts 

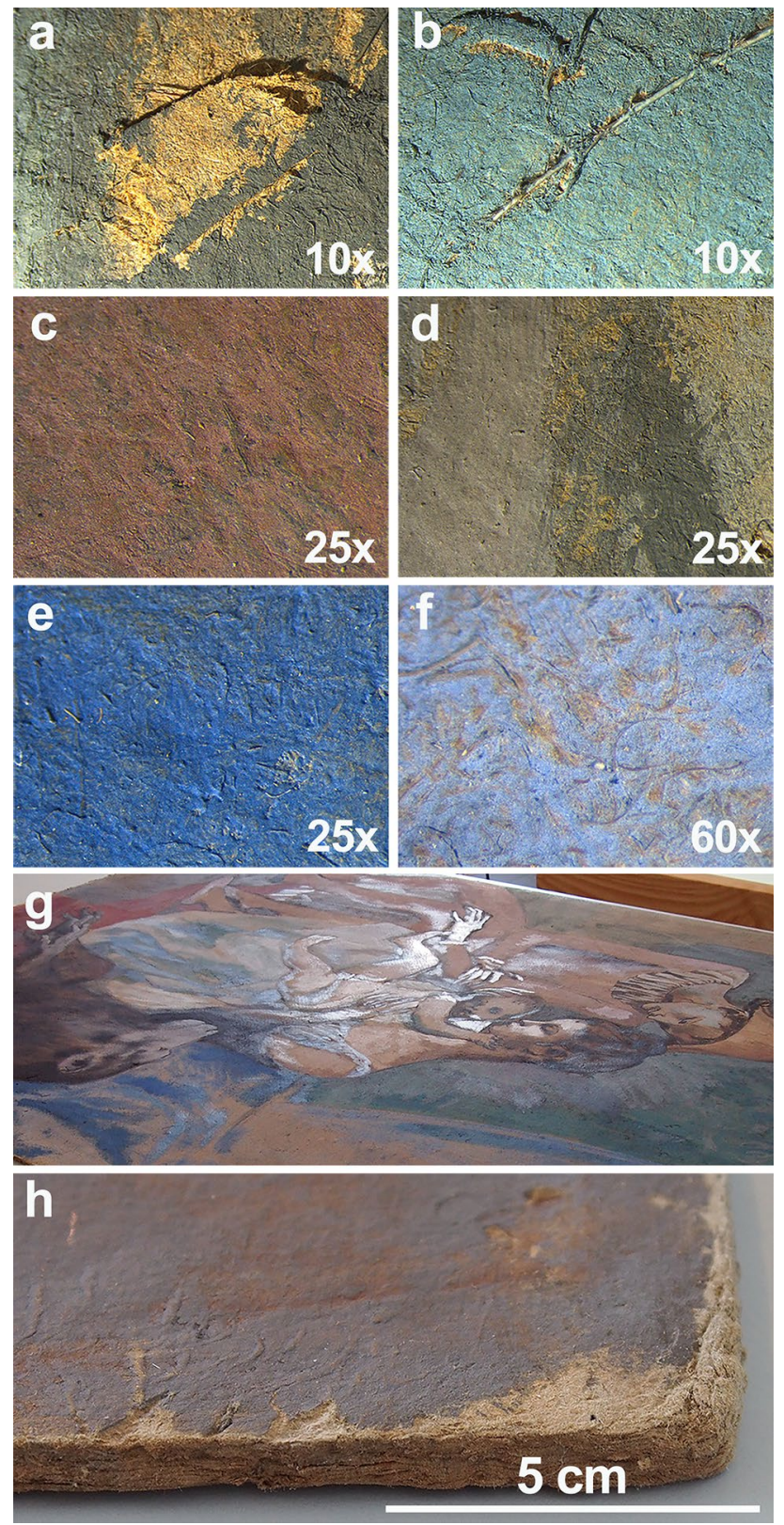

Fig. 2 Macrophotographs of details from the painting (a-f); image of the painting under reflected light $(\mathbf{g})$; detail of the corner showing delamination of the cardboard (h)

of $\mathrm{Zn}$ can be detected everywhere and the peak intensity in the painted areas is always weaker than in the cardboard. Therefore, $\mathrm{Zn}$ detected in the paint layer presumably comes from the cardboard support, rather than being associated with zinc-containing pigments (e.g. zinc white or lithopone).

FTIR and FORS spectra show signals of cellulosic material and kaolinite, the latter being commonly used as a filler [12]. In Fig. 3 a FTIR spectrum recorded of the cardboard support is compared to reference spectra of cellulose and

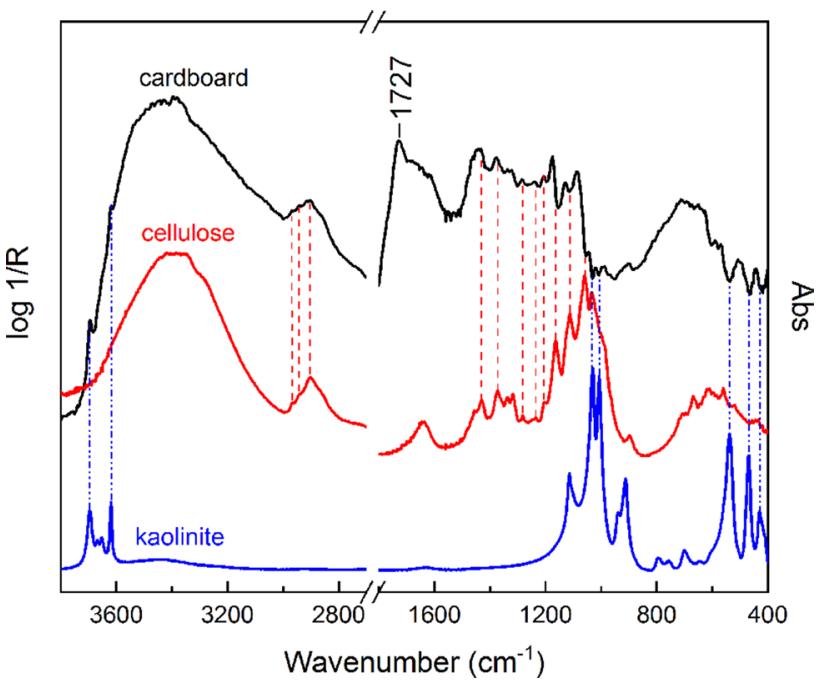

Fig. 3 Reflection FTIR spectrum of the cardboard support compared to reference spectra of kaolinite (blue line) and cellulose (red line) in transmission

kaolinite; the attribution of the diagnostic bands can be found in Cael et al. and Frost et al. [13, 14]. In addition, the presence of a carbonyl peak around $1727 \mathrm{~cm}^{-1}$ collected where the paint layer is absent, might indicate the presence of a sizing material. Although the position of the band suggests the use of a resin [15], the strong cellulose signals that dominate the spectrum preclude a more precise attribution.

Fibre analysis indicated that the cardboard is made of highly lignified mechanical wood pulp, with some traces of wool and cotton, as was typical of low-quality cardboard [9]. The board is slightly acidic, with a pH level of 5.5-6. Historically, much of the paper that was manufactured between 1820 and 1990 is acidic because of the additives used during the manufacture [16]. Furthermore, fibres have a high lignin content which easily degrades into acidic products, speeding up the degradation process of the paper material $[17,18]$.

Concerning the painting technique, differences in the $\mathrm{C}-\mathrm{H}$ signals shapes and positions-sometimes in association with a carbonyl band-indicate at least three different types of binding media. Two of them can be connected with the variable appearance of the paint layer: the matt surface shows strong and very sharp C-H signals at 2849, 2923 and 2954 (shoulder) $\mathrm{cm}^{-1}$ possibly indicating a waxy compound; and the shiny surface shows quite broad $\mathrm{C}-\mathrm{H}$ signals at 2831 and $2954 \mathrm{~cm}^{-1}$ (medium intensity), possibly suggesting drying oil (Fig. 4a) [15]. The third type of binder seems associated to the faded blue paint of the curtain (spectrum not shown) and has been possibly identified as a polysaccharide compound (e.g. gum). Because the non-invasive identification of binders and varnishes 

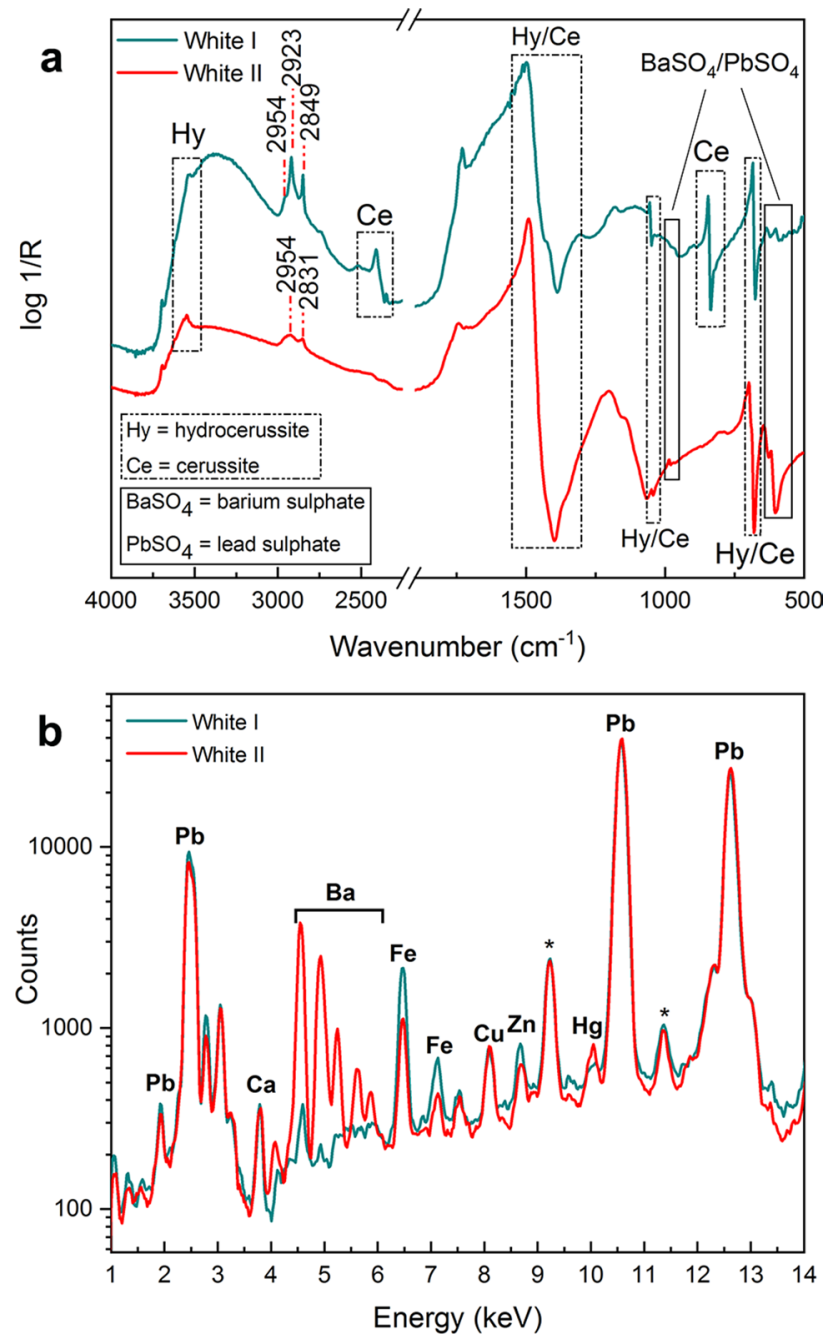

Fig. 4 Reflection FTIR (a) and XRF (b) spectra of White I and II. (* Lead escape peaks) by reflection FTIR is often challenging, conclusive indications about the essence technique cannot be given. At the same time, even the presence of other organic compounds cannot be excluded.

\subsection{White paint}

The analyses carried out on the white areas revealed the presence of two different types of paint (Fig. 4a, b):

- White I: lead white (mainly cerussite with small quantities of hydrocerussite), very small amounts of $\mathrm{Ba}$, probably barium sulphate, and possibly mixed with lead sulphate;

- White II: lead white (mainly hydrocerussite with small quantities of cerussite), large amounts of Ba, probably barium sulphate, and possibly mixed with lead sulphate;

The two types of white paints were used by Picasso in combination with other pigments and can be detected in other areas all over the painting. The attribution of the FTIR bands are based on Miliani et al. [19] and the references therein.

\subsection{Red and pink paint}

The presence of large amounts of mercury $(\mathrm{Hg})$ and an inflection point around $591 \mathrm{~nm}$ in the FORS spectra (due to an electronic transition from the valence to the conduction band) (Fig. 5a) indicate that vermilion was used to paint the majority of the red areas (Red I) [20]. The only exceptions are two dark red areas at the back of the monkey (Red II), where FORS spectra show two minima at ca. 519-22 and 551-55 nm (Fig. 5b) due to electronic transitions among delocalised molecular orbitals, indicating the
Fig. 5 FORS spectrum of Red I and its first derivative (a); FORS spectrum of Red II (b)
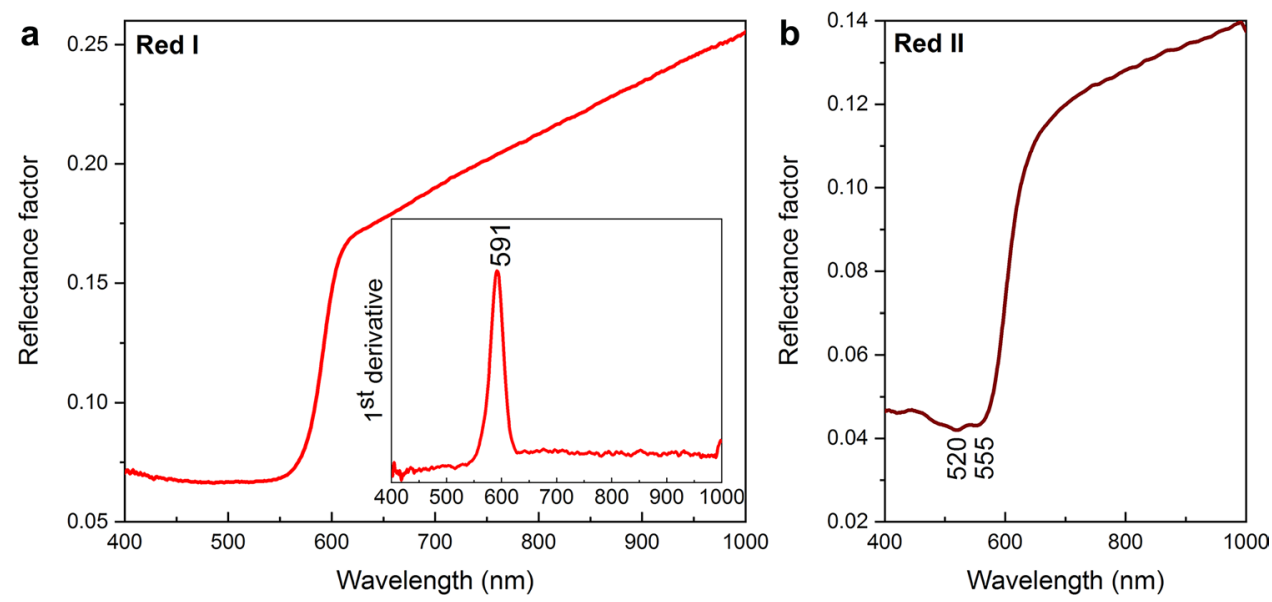

SN Applied Sciences a SPRINGer Nature journal 
presence of an anthraquinone-derived lake (very likely of animal origin, such as carmine, kermes, lac etc.) [11]. Very small amounts of $\mathrm{Hg}$ have been detected almost everywhere, also in areas that are not red, suggesting the sparse use of vermilion or unintentional contamination.

Variable amounts of lead white and vermilion were mixed together to create different shades of pink, which were used to paint the flesh tone, the shoes of the woman and other details.

\subsection{Black, grey and brown paint}

Mainly two pigments were used to paint black, grey and brown areas: bone/ivory black (infrared peak at $2015 \mathrm{~cm}^{-1}$, sometimes accompanied by features attributed to phosphate compounds and associated with large amounts of Ca together with small amounts of phosphorous $(P))$ and Prussian blue (C-N band around $2096 \mathrm{~cm}^{-1}$ [21-23]).

Some areas (Black I, Grey I, Brown I) are painted using both pigments, while in others (Black II, Grey II, Brown II) only Prussian blue has been detected. The presence of lead white in all the above-discussed areas (high amounts of $\mathrm{Pb}$ and specific FTIR bands, not showed) plausibly indicates that this pigment was added to achieve different tonalities. Variable amounts of $\mathrm{Hg}$ can be found everywhere as well, although FORS possibly suggests the presence of vermilion only in the brown hues. The complex composition of this neutral-brownish hue shows the wish of Picasso to mix different pigments to obtain a final desired chromatic effect. This ability has been also reported in paintings of his early career, previous to the Rose period [24]. An important aspect of Picasso's technique in Acrobat Family is the occurrence of bone/ivory black and Prussian blue which are often used in mixtures. As reported by Sessa et al. this fact seems to be a common feature of Picasso's early works [24].

\subsection{Green paint}

Two types of "greenish" paint have been identified on the painting: the first, detected on the dress of the woman and the face of the child (Green I); the second, detected on the background (Green II). In both greens, FTIR spectra show a strong C-N band around $2096 \mathrm{~cm}^{-1}$ and FORS detects a visible absorption band between 600 and $800 \mathrm{~nm}$ indicative of Prussian blue (Fig. 6a, b) $[23,25]$. A yellow component that is most probably yellow ochre, absorbs below $600 \mathrm{~nm}$ and is characterized by an inflection point at ca. $545 \mathrm{~nm}$; this has been detected by FORS only in Green I [11]. This component induces a blue shift of the Prussian blue minimum of absorption from 680 to $660 \mathrm{~nm}$. On the other hand, no yellow colorants have been clearly detected in Green II, which was probably produced by applying a diluted blue paint to the cardboard. The colour of Green II is therefore achieved by playing with the transparency of the paint and the yellowish colour of the support. However, the additional presence of a tiny amount of a yellow dye in Green II cannot be totally excluded, but the detection and identification of this type of compound by noninvasive means is difficult to achieve.

\subsection{Blue paint}

Two blue pigments were used by Picasso to paint the curtain, which is the area mostly affected by discolouration (Fig. 7a, b): the dark compound, highly absorbing in the IR image and appearing green in IRFC, is Prussian blue (Blue I); the compound transparent in IR, which turns pink/red in IRFC, is ultramarine blue (Blue II) (Fig. 7a). The former is characterized by a band around $2100 \mathrm{~cm}^{-1}$ in the FTIR spectrum and by a broad minimum around $700 \mathrm{~nm}$ in the visible spectrum due to an electron charge transfer between $\mathrm{Fe}^{\mathrm{II}}$ and Fe $\mathrm{F}^{\mathrm{III}}$ bridged by the cyano ligand; the
Fig. 6 Reflection FTIR (a) and FORS (b) spectra of Green I and II
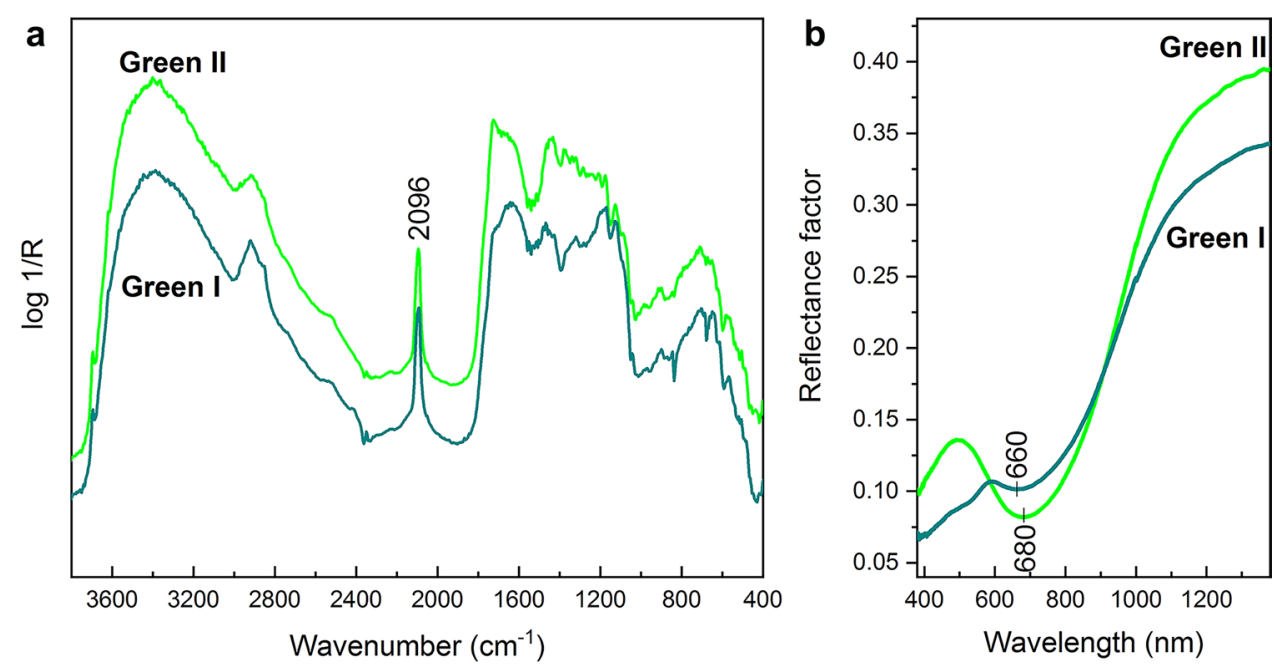


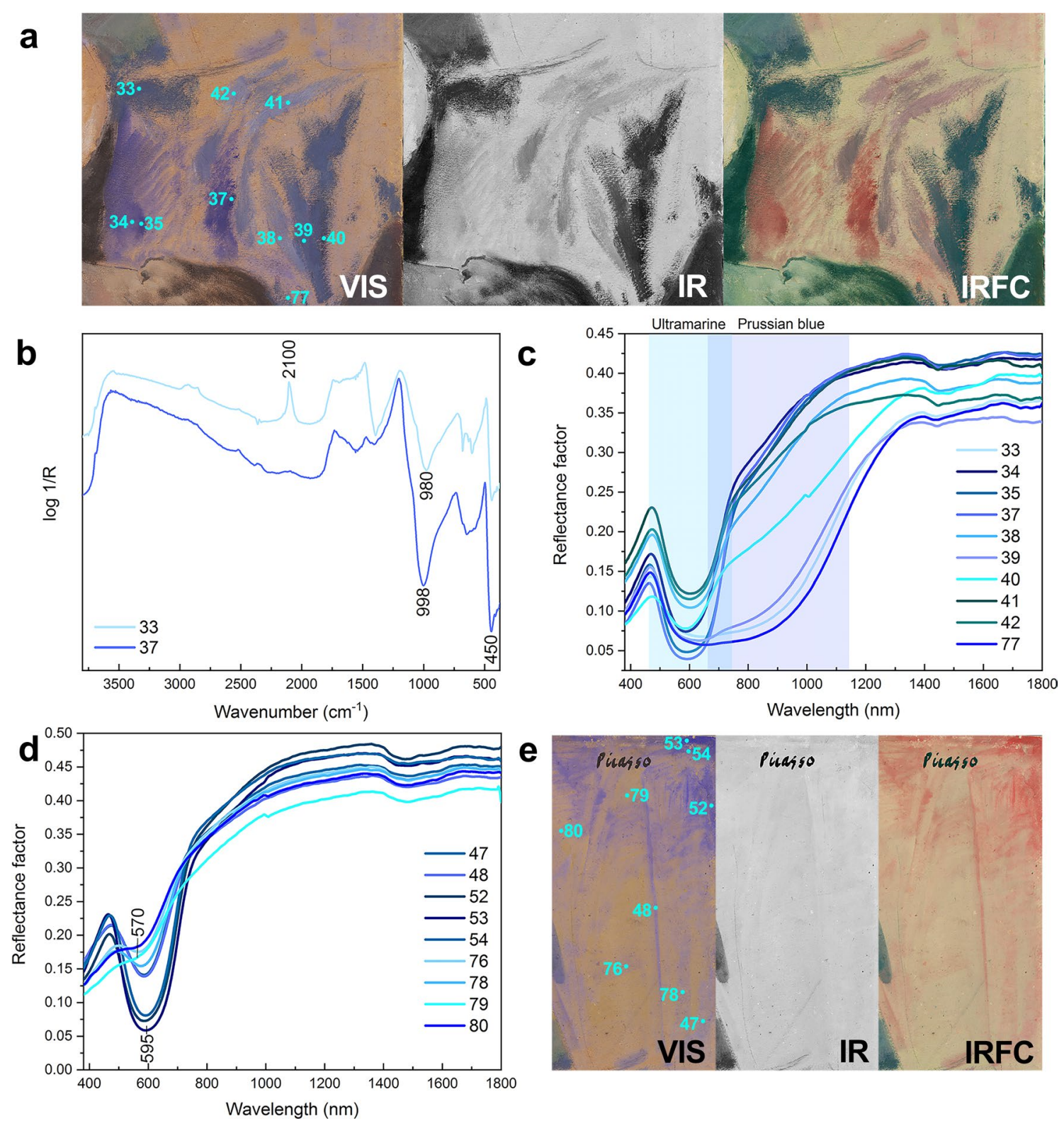

Fig. 7 Detail of the lower part of the curtain (a). FTIR (b) and FORS (c) spectra of blue areas painted with different mixtures of Blue I and II. FORS spectra of blue faded areas (d). Detail of the upper part of the curtain (e)

latter can be easily identified thanks to a FORS absorption band around $600 \mathrm{~nm}$ ascribed to the $\mathrm{S}_{3}{ }^{-}$radical anion trapped in the sodalite cage framework and to FTIR bands at 450 and $980-998 \mathrm{~cm}^{-1}$ attributed to Si-O vibrations (Fig. 7b, c) [19, 23, 25, 26].

The two pigments are often found together in the lower part of the curtain, suggesting that Picasso mixed them in various proportions to create different shades (the relative intensities of the respective Vis-NIR bands correspond to the relative amounts of the two blues) (Fig. 7c). Conversely, ultramarine blue is the main pigment in the upper part of the curtain, whereas Prussian blue is negligible. Weak signals of ultramarine blue in the FORS spectra are still detected even in the most faded areas, where the pigment is barely visible by the naked eye (Fig. 7d, e).

Both pigments are known to be characterized by fading and discolouration problems. The poor lightfastness of Prussian blue has been observed since late mid-nineteenth century. The pigment was reported to have the tendency to fade upon exposure to light when mixed with white pigments $[27,28]$. The fading is due to a photo-redox process that breaks the electron transfer $\mathrm{Fe}^{\text {II-CN-Fe }}$-III pathway and it can be variably affected by the compresence of other compounds (extenders, fillers, 
pigments), the substrates (canvas, paper), the environmental conditions and the manufacturing procedure [29-31].

The discolouration of ultramarine blue can be generated either by micro-fissures around the pigment particles in the paint layer (resulting from the disintegration of the binder), which scatter the light and make the paint surface appear patchy and whitish [32], or by the destruction of the sodalite cage framework (caused by both alkaline and acidic environment), which in turn triggers the release of the chromophores responsible for the colour [33-35].

\section{Conclusions}

The non-invasive analytical campaign provided valuable information on the material composition of the Acrobat Family, unveiling Picasso's palette and helping clarify some of the uncertainties about his painting technique. The latter aspect still presents open questions (i.e. essence, gouache and/or other binders) and further research, including the possibility of sampling for specific analyses, will be pursued.

From the conservation point of view, this study proved that several concurrent factors are probably responsible for the discolouration of the Acrobat Family. The main extrinsic one is excessive light exposure, mainly affecting the Prussian blue. The intrinsic ones are the paint composition itself (fillers, extenders, other pigments) and, especially for the ultramarine blue, the acidity of the support.

The acidity of the cardboard cannot be controlled or mitigated in this specific case. Due to the presence of the paint layer, de-acidification procedures of the support cannot be carried out. De-acidification is a common strategy to block the chemical mechanism of hydrolysis of cellulose and to slow down the rate of paper degradation $[36,37]$. However, in the case of the Acrobat Family, because of the importance of the artwork, introducing alkaline agents that could interfere with the chemical stability of the pigments was considered too risky.

The external factors, on the other hand, can be controlled to preserve the materiality and the identity of this masterpiece. Until 2008, the room where the painting is on display received indirect day light from a small rooftop window covered with a grey curtain. After the roof had been renovated, the window was removed and lighting was obtained with halogen lamps. In 2010, halogen lamps were replaced by LEDs. Therefore, controlled lighting in the exhibition rooms, in house and during loans, is a policy already adopted by the museum. In addition, a microclimate frame has now been built to protect the painting from fluctuations of the outside $\mathrm{RH}$-conditions and from mechanical damages. Finally, to reduce levels of gases and particulate air pollution, active carbon cloth could be added to the enclosure.

Acknowledgements The authors would like to thank the Musée d'Orsay and Fondation Beyeler for helping to fund the project, Hossein Sehatlou for his collaboration in the photo documentation, Susanne Stenbäcken and Anders Hammarstrand for assistance in the conservation of the original frame. Sponsorship from the Museu Picasso, Barcelona, to cover permission fees for the reproduction of works by Picasso is gratefully acknowledged.

\section{Compliance with ethical standards}

Conflict of interest statement On behalf of all authors, the corresponding author states that there is no conflict of interest.

\section{References}

1. Gothenburg Museum of Art (2019) The Picasso Room. https ://goteborgskonstmuseum.se/en/the-collection/the-picas so-room/

2. Guillaume Apollinaire, 'Les Jeunes: Picasso, peintre', La Plume, 15 May 1905, translated in A Picasso Anthology: Documents, Criticism, Reminiscences (1981). Arts Council of Great Britain, Musée Picasso, Paris, Hayward Gallery, London

3. McCully M, Staller NE (1997) Picasso, the early years, 1892-1906. National gallery of art, Washington

4. Bishop JC, Debray C, Rabinow RA (2011) The Steins collect: Matisse, Picasso, and the Parisian avant-garde. San Francisco Museum of Modern Art, San Francisco

5. Le Bon L, Bernardi C, Molins S, Philippot E (2018) Picasso. Bleu et Rose (Catalogue d'exposition). Editions Hazan

6. SanstøI Wollebæk J (1988) Henrik Sørensen og Göteborg-mesénene. Konsthistorisk tidskrift/J Art Hist 57:49-54

7. Tinterow G, Stein SA (eds) (2010) Picasso in the metropolitan musem of art. The metropolitan musem of art, New York; Yale University Press, New Haven and London

8. King A, Townsend JH, Ormsby B (2017) Girl in a Chemise c.1905 by Pablo Picasso. Tate Papers. https://www.tate.org.uk/research/ publications/tate-papers/28/picasso-girl-chemise

9. Papa E (2017) Picasso Under Investigation - Condition Assessment of the Acrobat Family by Pablo Picasso. Bachelor's Thesis in Conservation of Cultural Heritage Objects - University of Gothenburg

10. Frey F, Heller D, Kushel D, Vitale T, Weaver G (2017) The AIC guide to digital photography and conservation documentation. In: Warda J (ed). Washington

11. Aceto $M$, Agostino A, Fenoglio G, Idone A, Gulmini M, Picollo M, Ricciardi P, Delaney JK (2014) Characterisation of colourants on illuminated manuscripts by portable fibre optic UV-visible-NIR reflectance spectrophotometry. Anal Methods 6(5):1488. https ://doi.org/10.1039/c3ay41904e

12. Bundy WM, Ishley JN (1991) Kaolin in paper filling and coating. Appl Clay Sci 5(5-6):397-420

13. Cael J, Gardner K, Koenig J, Blackwell J (1975) Infrared and Raman spectroscopy of carbohydrates. Paper V. Normal coordinate analysis of cellulose I. J Chem Phys 62(3):1145-1153

14. Frost RL (1995) Fourier transform Raman spectroscopy of kaolinite, dickite and halloysite. Clays Clay Miner 43(2):191-195 
15. Derrick M (1989) Fourier transform infrared spectral analysis of natural resins used in furniture finishes. J Am Inst Conserv 28:43-56

16. Gurnagul N, Howard R, Zou X, Uesaka T, Page D (1993) The mechanical permanence of paper: a literature review. J Pulp Pap Sci 19:J160-J160

17. Area MC, Cheradame H (2011) Paper aging and degradation: recent findings and research methods. BioResources 6(4):5307-5337

18. Shahani CJ, Harrison G (2002) Spontaneous formation of acids in the natural aging of paper. Stud Conserv 47(sup3):189-192

19. Miliani C, Rosi F, Daveri A, Brunetti B (2012) Reflection infrared spectroscopy for the non-invasive in situ study of artists' pigments. Appl Phys A 106(2):295-307

20. Pallipurath AR, Skelton JM, Ricciardi P, Elliott SR (2016) Estimation of semiconductor-like pigment concentrations in paint mixtures and their differentiation from paint layers using firstderivative reflectance spectra. Talanta 154:63-72

21. Tomasini E, Siracusano G, Maier M (2012) Spectroscopic, morphological and chemical characterization of historic pigments based on carbon. Paths for the identification of an artistic pigment. Microchem J 102:28-37

22. Vila A, Ferrer N, García JF (2007) Chemical composition of contemporary black printing inks based on infrared spectroscopy: Basic information for the characterization and discrimination of artistic prints. Anal Chim Acta 591(1):97-105

23. Ware M (2004) Cyanotype: the history, science and art of photographic printing in Prussian blue. Gardners Books, Eastbourne

24. Sessa C, Jiménez de Garnica R, Rosi F, Fontana R, Garcia JF (2016) A Study of Picasso's Painting Materials and Techniques in Six of His Early Portraits. J Am Inst Conserv 55(4):198-216

25. Bacci M, Magrini D, Picollo M, Vervat M (2009) A study of the blue colors used by Telemaco Signorini (1835-1901). J Cult Herit 10(2):275-280. https://doi.org/10.1016/j.culher.2008.05.006

26. Aceto M, Agostino A, Fenoglio G, Picollo M (2013) Non-invasive differentiation between natural and synthetic ultramarine blue pigments by means of 250-900 nm FORS analysis. Anal Methods 5(16):4184. https://doi.org/10.1039/c3ay40583d

27. Kirby J (1993) Fading and colour change of Prussian blue: occurrences and early reports. Natl Gallery Tech Bull 14(1):62-71
28. Kirby J, Saunders D (2004) Fading and colour change of Prussian blue: methods of manufacture and the influence of extenders. Natl Gallery Tech Bull 25(1):73-99

29. Samain L, Grandjean F, Long GJ, Martinetto P, Bordet P, Strivay D (2013) Relationship between the synthesis of Prussian blue pigments, their color, physical properties, and their behavior in paint layers. J Phys Chem C 117(19):9693-9712

30. Samain L, Gilbert B, Grandjean F, Long GJ, Strivay D (2013) Redox reactions in Prussian blue containing paint layers as a result of light exposure. J Anal At Spectrom 28(4):524-535

31. Gervais C, Languille M-A, Réguer S, Gillet M, Pelletier S, Garnier C, Vicenzi EP, Bertrand L (2013) Why does Prussian blue fade? Understanding the role (s) of the substrate. J Anal At Spectrom 28(10):1600-1609

32. de la Rie ER, Michelin A, Ngako M, Del Federico E, Del Grosso C (2017) Photo-catalytic degradation of binding media of ultramarine blue containing paint layers: a new perspective on the phenomenon of "ultramarine disease" in paintings. Polym Degrad Stab 144:43-52

33. Del Federico E, Newman J, Tyne L, O'Hern C, Isolani L, Jerschow A (2006) Solid-State NMR Studies Of Ultramarine Pigments Discoloration. MRS Online Proceedings Library Archive 984

34. Del Federico E, Shöfberger W, Schelvis J, Kapetanaki S, Tyne L, Jerschow A (2006) Insight into framework destruction in ultramarine pigments. Inorg Chem 45(3):1270-1276

35. Plesters J (1993) Ultramarine blue, natural and artificial. In: Roy A (ed) Artists' pigments - a handbook of their history and characteristics, vol 2. National gallery of art, New York, pp 37-62

36. Baty JW, Maitland CL, Minter W, Hubbe MA, Jordan-Mowery SK (2010) Deacidification for the conservation and preservation of paper-based works: a review. BioResources 5(3):1955-2023

37. Zervos S, Alexopoulou I (2015) Paper conservation methods: a literature review. Cellulose 22(5):2859-2897

Publisher's Note Springer Nature remains neutral with regard to jurisdictional claims in published maps and institutional affiliations. 